\title{
VUV/UV/Chlorine as an Enhanced Advanced Oxidation Process for Organic Pollutant Removal from Water: Assessment with a Novel Mini-Fluidic VUV/UV Photoreaction System (MVPS)
}

Mengkai Li, ${ }^{\dagger, \ddagger}$ Zhimin Qiang, ${ }^{*}, \dagger$ Pin Hou, ${ }^{\S}$ James R. Bolton, ${ }^{\dagger}$ Jiuhui Qu, ${ }^{\dagger \dagger}$ Peng Li, ${ }^{\S}$ and Chen Wang,

${ }^{\dagger}$ Key Laboratory of Drinking Water Science and Technology, Research Center for Eco-Environmental Sciences, Chinese Academy of Sciences, 18 Shuang-qing Road, Beijing 100085, China

"University of Chinese Academy of Sciences, 19 Yu-quan Road, Beijing 100049, China

${ }^{\S}$ School of Chemical and Environmental Engineering, China University of Mining and Technology, Beijing 100083, China

"Department of Civil and Environmental Engineering, University of Alberta, Edmonton, Alberta T6G 2W2, Canada

\section{Supporting Information}

ABSTRACT: Vacuum ultraviolet (VUV) and ultraviolet (UV)/chlorine processes are regarded as two of many advanced oxidation processes (AOPs). Because of the similar cost of VUV/UV and UV lamps, a combination of VUV and $\mathrm{UV} /$ chlorine (i.e., $\mathrm{VUV} / \mathrm{UV} /$ chlorine) may enhance the removal of organic pollutants in water but without any additional power input. In this paper, a minifluidic VUV/UV photoreaction system (MVPS) was developed for bench-scale experiments, which could emit both VUV $(185 \mathrm{~nm})$ and UV $(254 \mathrm{~nm})$ or solely UV beams with a nearly identical UV photon fluence. The photon fluence rates of UV and VUV output by the MVPS were determined to be $8.88 \times 10^{-4}$ and 4.93 $\times 10^{-5}$ einstein $\mathrm{m}^{-2} \mathrm{~s}^{-1}$, respectively. The $\mathrm{VUV} / \mathrm{UV} /$ chlorine process exhibited a strong enhancement concerning the degradation of methylene blue ( $\mathrm{MB}$, a model organic pollutant) as compared to the total performance of the VUV/UV and $\mathrm{UV} /$ chlorine processes, although the photon fluence of the VUV only accounted

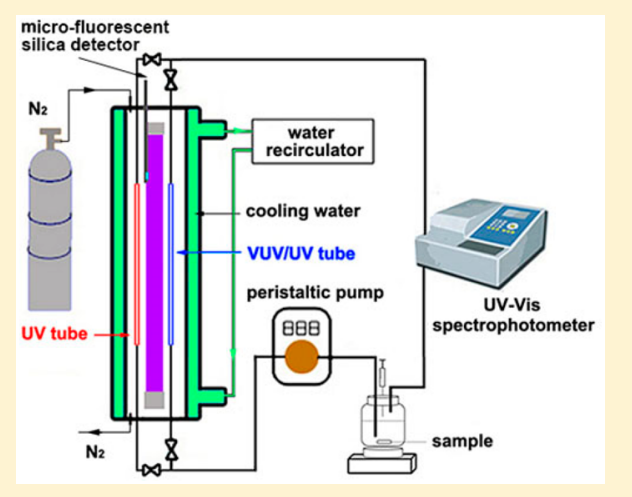
for $5.6 \%$ of that of the UV. An acidic $\mathrm{pH}$ favored $\mathrm{MB}$ degradation by the VUV/ $\mathrm{UV} /$ chlorine process. The synergistic mechanism of the $\mathrm{VUV} / \mathrm{UV} /$ chlorine process was mainly ascribed to the effective use of ${ }^{\bullet} \mathrm{OH}$ for pollutant removal through formation of longer-lived secondary radicals (e.g., ${ }^{\bullet} \mathrm{OCl}$ ). This study demonstrates that the new VUV/UV/chlorine process, as an enhanced AOP, can be applied as a highly effective and energy-saving technology for small-scale water and wastewater treatment.

\section{INTRODUCTION}

Advanced oxidation processes (AOPs) involving the generation of hydroxyl radicals $\left(\bullet^{\bullet} \mathrm{OH}\right)$ can effectively degrade recalcitrant organic constituents in water and wastewater treatment. ${ }^{1}$ The combined use of ultraviolet and free chlorine (UV/chlorine), two commonly applied disinfection methods, has been regarded as an effective AOP for inactivation of water-borne pathogens and decomposition of hazardous organic compounds. ${ }^{2-6}$ Many studies have reported the fast degradation of organic pollutants by the UV/chlorine process, which involves a series of chain reactions with the formation of both ${ }^{\bullet} \mathrm{OH}$ and chlorine radicals $\left(\mathrm{Cl}^{\circ}\right)$ as highly reactive species: ${ }^{4,6,7}$

$$
\begin{aligned}
& \mathrm{HOCl} \rightleftharpoons \mathrm{H}^{+}+\mathrm{OCl}^{-}, \quad \mathrm{pK} K_{\mathrm{a}}=7.5\left(25^{\circ} \mathrm{C}\right) \\
& \mathrm{HOCl} \stackrel{h v_{254}}{\longrightarrow} \mathrm{OH}+\mathrm{Cl}^{\bullet} \\
& \mathrm{OCl}^{-} \stackrel{h v_{254}}{\longrightarrow} \mathrm{O}^{\bullet-}+\mathrm{Cl}^{\bullet} \\
& \mathrm{O}^{\bullet-}+\mathrm{H}_{2} \mathrm{O} \rightarrow \stackrel{\circ}{\mathrm{OH}}+\mathrm{OH}^{-}
\end{aligned}
$$

Vacuum ultraviolet (VUV) covers a wavelength range from 100 to $200 \mathrm{~nm}$. Photo-oxidation with VUV is also considered as an AOP because these photons can be absorbed by water with a high absorption coefficient (e.g., $1.8 \mathrm{~cm}^{-1}$ at $185 \mathrm{~nm}$ ) to produce ${ }^{\bullet} \mathrm{OH}:^{8}$

$$
\mathrm{H}_{2} \mathrm{O} \stackrel{h v_{185}}{\longrightarrow} \mathrm{OH}+\mathrm{H}^{\bullet}
$$

It is known that low-pressure (LP) mercury lamps are typically designed to emit only $254 \mathrm{~nm}$ UV light (useful for disinfection), whereas the simultaneously emitted $185 \mathrm{~nm}$ VUV light is purposely absorbed by the lamp wall made of $\mathrm{Ti}$ doped quartz to avoid the generation of ozone. However, if a high-purity synthetic quartz is used, ${ }^{9,10}$ then both $185 \mathrm{~nm}$ VUV and $254 \mathrm{~nm}$ UV (i.e., VUV/UV) beams can penetrate the lamp wall. Direct VUV photolysis of water can produce an

Received: January 10, 2016

Revised: $\quad$ May 14, 2016

Accepted: May 17, 2016

Published: May 17, 2016 
appreciable amount of ${ }^{\bullet} \mathrm{OH}$ for oxidative decomposition of organic pollutants without any additional power input. As a result, the VUV/UV process has been applied to enhance the disinfection of pathogens and the removal of dissolved organic matter and various micropollutants in water and wastewater. $^{11-15}$ For UV-based AOPs (e.g., UV/chlorine), if a VUV/UV LP lamp (using synthetic quartz) is used as the light source, a higher efficiency can be expected than for a conventional UV LP lamp.

Because of the low penetration depth of VUV in air (about $50 \mathrm{~mm}$ ), the traditional quasi-collimated beam apparatus is inapplicable to the study of bench-scale VUV reactions in aqueous solution, except that a few researchers have attempted to improve its design by placing the whole apparatus in a $\mathrm{N}_{2}$ filled box. ${ }^{16,17}$ Hence, most previous studies were conducted in annular batch reactors with a VUV/UV lamp (10-500 W) situated in the center. Moreover, these batch reactors were usually operated in a recirculating mode for sample collection at various reaction times (or photon fluences). ${ }^{18-20}$

However, batch VUV/UV reactors have some problems in bench-scale studies. First, the LP lamp emits both VUV (185 $\mathrm{nm})$ and UV (254 $\mathrm{nm})$ beams, so it is difficult to distinguish the contribution of each wavelength. Especially for the VUV/UVbased AOPs, the UV component often plays an important role in ${ }^{\bullet} \mathrm{OH}$ generation. Hence, to accurately assess the effect of the VUV component, a special apparatus is needed that can output an identical UV photon fluence for both VUV/UV and UV tests. If a VUV/UV LP lamp and a UV LP lamp are used alternately in the same apparatus, then one cannot ensure an identical UV photon fluence of the two lamps because many factors (e.g., power input, ballast quality, and operational conditions) may influence the lamp output. Moreover, because the VUV only comprises a small fraction of the total lamp output (i.e., about $5-8 \%$ of the UV output) and has a low transmittance in air, quartz sleeves are not used in many batch $\mathrm{VUV} / \mathrm{UV}$ reactors so as to maximize the VUV output. However, without protection of the quartz sleeve that helps stabilize the lamp surface temperature, the fluctuation in lamp output can induce an enlarged uncertainty in bench-scale kinetic studies. ${ }^{21,22}$ In addition, it is difficult to determine accurately the photon fluence because of the nonuniform distribution of photon fluence rate (PFR) in batch VUV/UV reactors. Therefore, it is desirable to have a new bench-scale VUV/UV apparatus for relevant photoreaction studies.

In this study, a mini-fluidic VUV/UV photoreaction system (MVPS) was developed for bench-scale photochemical experiments, in which a lamp could deliver either the combined VUV/UV (i.e., 185/254 nm) beams or the sole UV beam with a nearly identical UV photon fluence. A UV-vis spectrophotometer was installed in the MVPS to provide online absorbance measurements or spectral scans of water samples. On the basis of the newly developed MVPS, this study further explored qualitatively the impact of VUV on the UV/chlorine process with regard to the photodegradation kinetics of organic pollutants in aqueous solution. Methylene blue (MB) was selected as a model pollutant because its concentration can be easily measured at $664 \mathrm{~nm}$ with the online spectrophotometer in the MVPS. The measurement at this wavelength could avoid the interference of $\mathrm{HOCl} / \mathrm{OCl}^{-}$. Besides, a synergistic mechanism of the $\mathrm{VUV} / \mathrm{UV} /$ chlorine process was proposed and experimentally assessed. This study demonstrates that the $\mathrm{VUV} / \mathrm{UV} /$ chlorine process, as an enhanced AOP, can remove organic pollutants effectively in water and wastewater treatment.

\section{EXPERIMENTAL SECTION}

Mini-Fluidic VUV/UV Photoreaction System (MVPS). To overcome the problems of batch VUV/UV reactors, a new apparatus, namely MVPS, was designed and fabricated for bench-scale photochemical studies, as illustrated in Figure 1.

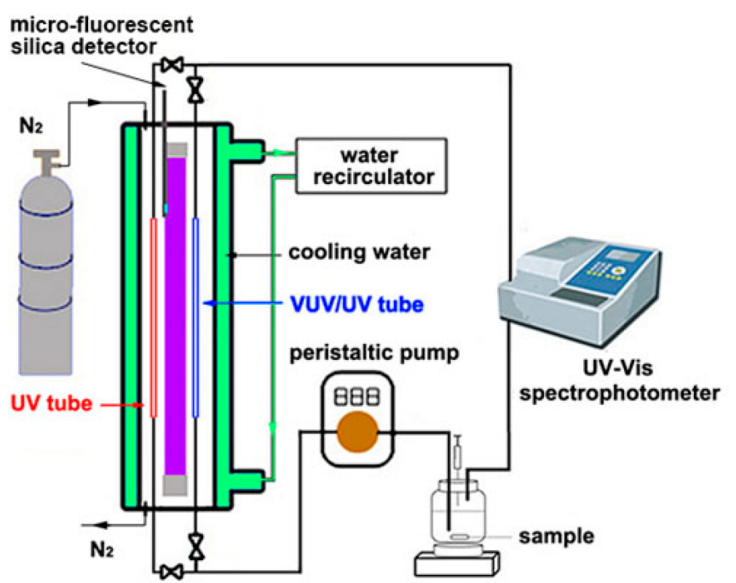

Figure 1. Schematic diagram of the mini-fluidic VUV/UV photoreaction system (MVPS).

The core part of the MVPS was a cylindrical and jacketed quartz-wall photoreactor (length $=300 \mathrm{~mm}$, outer diameter $=$ $40 \mathrm{~mm}$ ). Cooling water (i.e., deionized water) was recirculated through the outer chamber between two quartz walls to control a constant temperature of the photoreactor, thus ensuring stable VUV and UV outputs. An $8 \mathrm{~W}$ cold-cathode LP mercury lamp (arc length $=200 \mathrm{~mm}$, Wanhua Co., Zhejiang, China), manufactured with a high-purity synthetic quartz wall to emit both VUV $(185 \mathrm{~nm})$ and UV $(254 \mathrm{~nm})$ beams, was installed along the central axis of the cylindrical photoreactor.

A straight synthetic quartz tube [VUV/UV tube, high VUV transmittance (i.e., $60 \%$ per millimeter)] and a straight $\mathrm{Ti}$ doped quartz tube (UV tube, no VUV transmittance), both of 2 $\mathrm{mm}$ inner diameter and $100 \mathrm{~mm}$ length, were installed parallel to the lamp at the same radial distance (about $5 \mathrm{~mm}$ ) to the lamp surface (Figure 1). By this design, the water sample in the UV tube could only receive the sole UV exposure, while that in the $\mathrm{VUV} / \mathrm{UV}$ tube could receive the combined VUV/UV exposure. Furthermore, a nearly identical UV photon fluence could be achieved in the VUV/UV and UV tubes because both had a high UV $(254 \mathrm{~nm})$ transmittance and the same distance to the lamp surface. Note that the two tubes should avoid the end-lamp regions (i.e., the last $50 \mathrm{~mm}$ at each end of the lamp arc) where the PFR distribution is usually nonuniform. ${ }^{23}$ Nitrogen gas was flushed through the inner chamber of the photoreactor, which avoided the absorption of VUV by the interior air to produce ozone and thus maximized the VUV output. A microfluorescent silica detector (MFSD) was installed at about $5 \mathrm{~mm}$ to the lamp surface, which could monitor online any fluctuation in the UV output in each experiment. $^{23}$

A UV-vis spectrophotometer (UV2600, Shimadzu, Japan) with a continuous injection cell was connected to the VUV/UV and UV tubes to provide online spectrophotometric analysis. The water sample was pumped by a peristaltic pump 
sequentially through the exposure portion of the MVPS (i.e., the VUV/UV or UV tube) and through the spectrophotometer, and then recirculated to receive additional exposure until a desired photon fluence was reached. It should be pointed out that for a certain exposure time, only a part of water sample could receive the $\mathrm{VUV} / \mathrm{UV}$ or $\mathrm{UV}$ irradiation, while the remaining part was in the dark. Hence, by defining a reduction equivalent exposure time $\left(t_{\text {ree }}, \mathrm{s}\right)$ as the total reaction time $(t, \mathrm{~s})$ multiplied by the ratio of the exposure volume of the operation tube $\left(\pi r^{2} L, \mathrm{~m}^{3}\right)$ to the total sample volume $\left(V, \mathrm{~m}^{3}\right)$, the VUV $\left(F_{\mathrm{p}, \mathrm{o}, \mathrm{VUV}}\right.$, einstein $\left.\mathrm{m}^{-2}\right)$ or $\mathrm{UV}\left(F_{\mathrm{p}, \mathrm{o}, \mathrm{UV}}\right.$, einstein $\left.\mathrm{m}^{-2}\right)$ photon fluence can be readily calculated as follows: ${ }^{24}$

$$
\begin{aligned}
& t_{\text {ree }}=\frac{\pi r^{2} h}{V} t \\
& F_{\mathrm{p}, \mathrm{o}, \mathrm{UV}}=E_{\mathrm{p}, \mathrm{o}, \mathrm{UV}} t_{\text {ree }} \\
& F_{\mathrm{p}, \mathrm{o}, \mathrm{VUV}}=E_{\mathrm{p}, \mathrm{o}, \mathrm{VUV}} t_{\text {ree }}
\end{aligned}
$$

where $r$ and $h$ are the radius and length of the VUV/UV (or $\mathrm{UV}$ ) tube (m), respectively; and $E_{\mathrm{p}, \mathrm{o}, \mathrm{UV}}$ and $E_{\mathrm{p}, \mathrm{o}, \mathrm{VUV}}$ are the UV PFR in the UV or VUV/UV tube and the VUV PFR in the VUV/UV tube (einstein $\mathrm{m}^{-2} \mathrm{~s}^{-1}$ ), respectively. Hence, the total exposure photon fluence $\left(F_{\mathrm{p}, \mathrm{o}}\right.$, einstein $\left.\mathrm{m}^{-2}\right)$ in the VUV/UV tube is equal to the sum of $F_{\mathrm{p}, \mathrm{o}, \mathrm{VUV}}$ and $F_{\mathrm{p}, \mathrm{o}, \mathrm{UV}}$. In other words, $t_{\text {ree }}$ can be regarded as the exposure time when the whole sample receives the exposure with the same UV or VUV/UV $\operatorname{PFR}(s)$ in the relevant tube.

Chemicals and Analysis. Milli- $Q$ water (Advantage A10, Millipore, U.S.A.) was used in all experiments and analytical determinations. $\mathrm{MB}$ and uridine were purchased from SigmaAldrich (St. Louis, U.S.A.), whose concentrations were determined by absorbance measurements at 664 and $262 \mathrm{~nm}$ using the online spectrophotometer, respectively. The concentration of methanol (Sigma-Aldrich) was determined by gas chromatography equipped with a flame ionization detector (GC-FID, Shimadzu 2010, Japan). The concentration of $\mathrm{H}_{2} \mathrm{O}_{2}$ (Beijing Chemical Reagents Co., Beijing, China) was determined by the titanium oxysulfate $\left(\mathrm{TiOSO}_{4}\right.$, Fluka) method with a detection limit of $0.01 \mathrm{mg} \mathrm{L}^{-1} \cdot{ }^{25}$ Active chlorine $\left(\mathrm{HOCl} / \mathrm{OCl}^{-}\right)$was prepared freshly from a stock $\mathrm{NaOCl}$ solution (10-15\% by weight, Sigma-Aldrich), and its concentration was measured by the $N, N$-diethyl-p-phenylenediamine colorimetric method on a UV-vis spectrophotometer (Hach DR5000, U.S.A.). ${ }^{26}$ To scavenge ${ }^{\circ} \mathrm{OH}, 5 \mathrm{mM}$ tertbutanol (TBA, Sigma-Aldrich) or $0.5 \mathrm{mM}$ nitrobenzene (NB, Sigma-Aldrich) was added to relevant reaction solutions in advance.

Experimental Procedures. Each experiment was initiated after warming up the lamp for about 15 min until the MFSD signal reached a constant value. Uridine ${ }^{27}(0.12 \mathrm{mM})$ or methanol $^{28,29}(95 \mathrm{mM})$ was used as the chemical actinometer to determine the $F_{\mathrm{p}, \mathrm{o} . \mathrm{UV}}$ and $F_{\mathrm{p}, \mathrm{o} . \mathrm{VuV}}$ in the MVPS, respectively. To assess the enhancement on MB degradation by the VUV/ $\mathrm{UV} /$ chlorine process as compared to the $\mathrm{UV} /$ chlorine process, an unbuffered $\mathrm{MB}$ solution $\left(5 \mathrm{mg} \mathrm{L}^{-1}\right)$ was spiked with $25 \mathrm{mg}$ $\mathrm{L}^{-1}$ (as active chlorine) $\mathrm{NaOCl}$ and immediately pumped through the VUV/UV and UV tubes to receive the irradiation. The solution $\mathrm{pH}$ decreased approximately from an initial value of 6.4 to a final value of 5.5 during the course of reaction. To examine the effect of $\mathrm{pH}$, the $\mathrm{MB}$ solution was buffered at either $\mathrm{pH} 5$ (with phosphate) or 10 (with borate) and then subjected to photodegradation in the $\mathrm{VUV} / \mathrm{UV} /$ chlorine and
$\mathrm{UV} /$ chlorine processes. According to its $\mathrm{p} K_{\mathrm{a}}$ at $25^{\circ} \mathrm{C}$ (i.e., 7.5), active chlorine at $\mathrm{pH}$ values of 5 and 10 consist of $99.7 \%$ and $0.3 \% \mathrm{HOCl}$, respectively. The MB concentration was measured by the online spectrophotometer at a time interval of $0.5 \mathrm{~min}$ during photodegradation experiments that lasted for $10 \mathrm{~min}$ each.

\section{RESULTS AND DISCUSSION}

Determination of $F_{\mathrm{p}, \mathrm{o}, \mathrm{Uv}}$ and $F_{\mathrm{p}, \mathrm{o}, \mathrm{Vuv}}$ in the MVPS. A uridine solution $(0.12 \mathrm{mM})$ was used as the chemical actinometer to determine the $F_{\mathrm{p}, \mathrm{o}, \mathrm{UV}}$ in the MVPS. Figure 2

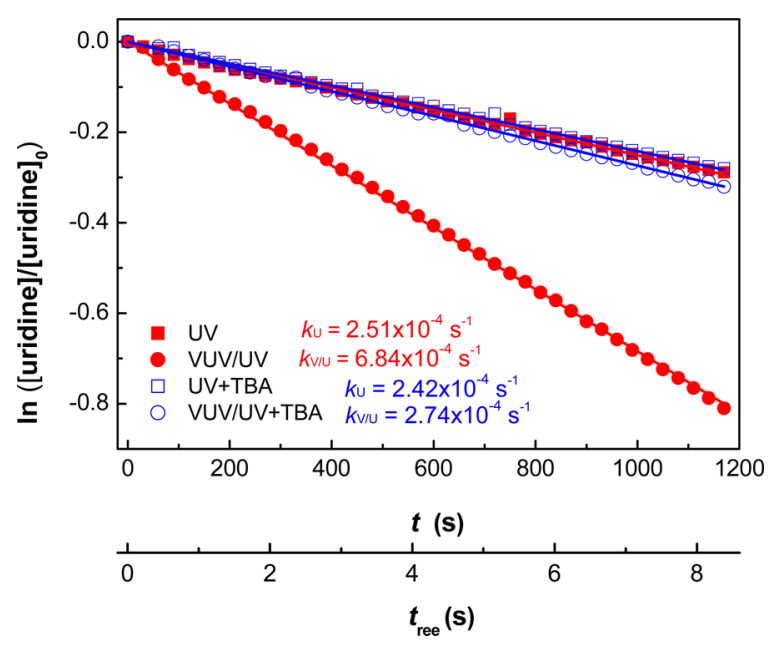

Figure 2. Photolysis of uridine in the presence or absence of TBA (5 $\mathrm{mM}$ ) in the VUV/UV and UV tubes.

shows the logarithmic decay of uridine with reaction time in each tube in the presence or absence of TBA (i.e., ${ }^{\circ} \mathrm{OH}$ scavenger). The fit lines indicate that each reaction could be well expressed by pseudo-first-order kinetics. In the UV tube, TBA addition had little impact on the reaction rate constant because of the negligible ${ }^{\bullet} \mathrm{OH}$ generation during the direct UV photolysis of uridine. In the VUV/UV tube, because VUV photons preferred to react with water (with a high concentration of $55.6 \mathrm{M}$ ) than with uridine, the direct VUV photolysis of uridine was insignificant. The total uridine decay was ascribed to both the direct UV photolysis and the oxidation by ${ }^{\bullet} \mathrm{OH}$ generated from the direct VUV photolysis of water. As a result, the uridine decay in the VUV/UV tube was obviously faster than in the UV tube (Figure 2). After scavenging ${ }^{\circ} \mathrm{OH}$ with TBA in the VUV/UV tube, the reaction rate constant of uridine $\left(2.74 \times 10^{-4} \mathrm{~s}^{-1}\right)$ was close to that in the UV tube $(2.51$ $\left.\times 10^{-4} \mathrm{~s}^{-1}\right)$, demonstrating that the UV and VUV/UV tubes had nearly identical $F_{\mathrm{p}, \mathrm{o}, \mathrm{UV}}$ values.

On the basis of the UV photolysis rate constant of uridine determined above, the $F_{\mathrm{p}, \mathrm{o}, \mathrm{UV}}$ (einstein $\mathrm{m}^{-2}$ ) could be calculated as follows:

$$
F_{\mathrm{p}, \mathrm{o}, \mathrm{UV}}=\frac{k_{\mathrm{u}}}{\ln (10) \times 0.1 \times \varepsilon_{\lambda} \times \Phi_{\mathrm{u}}} \times t
$$

where $k_{\mathrm{u}}\left(\mathrm{s}^{-1}\right)$ is the time-based pseudo-first-order rate constant for UV photolysis of uridine; and $\varepsilon_{\lambda}\left(\mathrm{M}^{-1} \mathrm{~cm}^{-1}\right)$ and $\Phi_{\mathrm{u}}$ are the decadic molar absorption coefficient and quantum yield of uridine at an exposure wavelength $(\lambda)$, respectively. The $\varepsilon_{254}$ and $\Phi_{\mathrm{u}}$ values were reported to be 8,775 $\mathrm{M}^{-1} \mathrm{~cm}^{-1}$ and 0.020 , respectively. ${ }^{27}$ Therefore, the UV PFR 
(i.e., $E_{\mathrm{p}, \mathrm{o}, \mathrm{UV}}$ ) was calculated to be $8.88 \times 10^{-4}$ einstein $\mathrm{m}^{-2} \mathrm{~s}^{-1}$ (or a fluence rate of $41.8 \mathrm{~mW} \mathrm{~cm}^{-2}$ ) at $254 \mathrm{~nm}$ from eqs 6 and $7(r=1 \mathrm{~mm}, h=100 \mathrm{~mm}, V=44 \mathrm{~mL})$.

In addition, a methanol solution $(95 \mathrm{mM})$ was used as another chemical actinometer to determine the $F_{\mathrm{p}, \mathrm{o}, \mathrm{VUV}}$ in the VUV/UV tube. Figure 3 shows that the VUV photolysis of

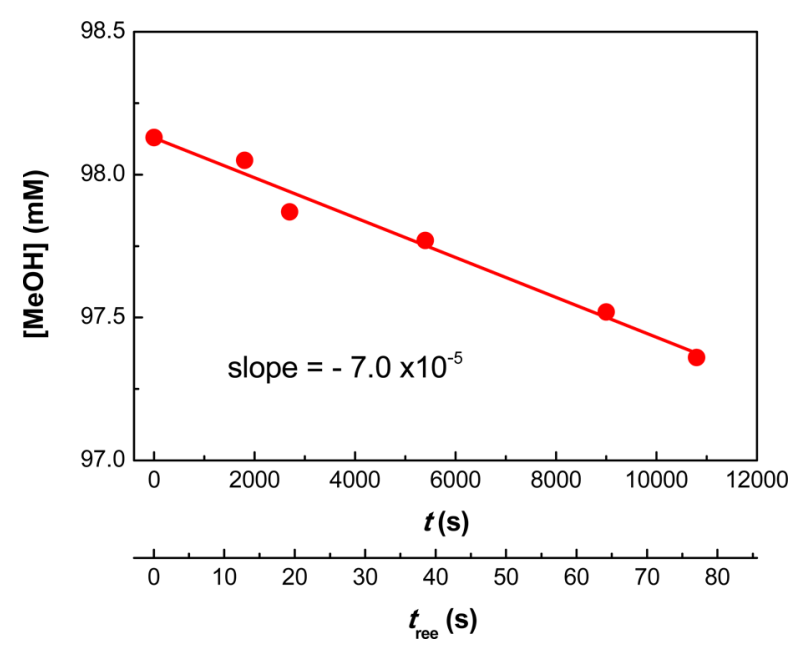

Figure 3. Photolysis of methanol $(\mathrm{MeOH})$ in the VUV/UV tube.

methanol could be well expressed by zero-order kinetics, and the rate constant of methanol degradation $\left(k_{\mathrm{MeOH}}\right)$ was $7.0 \times$ $10^{-8} \mathrm{M} \mathrm{s}^{-1}$. Hence, the VUV photon flux could be calculated with eq $10:^{28}$

$$
q_{\mathrm{VUV}}=\frac{k_{\mathrm{MeOH}} V}{0.946\left(\Phi_{\mathrm{H}_{2} \mathrm{O}} f_{\mathrm{H}_{2} \mathrm{O}}+\Phi_{\mathrm{MeOH}} f_{\mathrm{MeOH}}\right)}
$$

where $q_{\text {vuv }}$ is the absorbed VUV photon flux (einstein $\mathrm{s}^{-1}$ ); $\Phi_{\mathrm{H} 2 \mathrm{O}}$ and $\Phi_{\mathrm{MeOH}}$ are the total quantum yields of ${ }^{\circ} \mathrm{OH}$ generated from VUV photolysis of water $\left(\Phi_{\mathrm{H} 2 \mathrm{O}}=0.375\right)$ and methanol $\left(\Phi_{\mathrm{MeOH}}=1\right)$, respectively; ${ }^{30} f_{\mathrm{H} 2 \mathrm{O}}$ and $f_{\mathrm{MeOH}}$ are the incident photon fractions absorbed by water $\left(f_{\mathrm{H} 2 \mathrm{O}}=0.9962\right)$ and methanol $\left(f_{\mathrm{MeOH}}=0.0038\right)$, respectively; and the factor of 0.946 refers to the production of methanol by the disproportionation reaction of hydroxymethyl radicals which slows down the ${ }^{\bullet} \mathrm{OH}$-induced degradation of methanol. ${ }^{28}$ The VUV PFR (i.e., $E_{\mathrm{p}, \mathrm{o}, \mathrm{VUV}}$ ) at the outer surface of the VUV/UV tube was equal to the $q_{\mathrm{vuv}}$ divided by the cross-sectional area of the tube [i.e., $4.93 \times 10^{-5}$ einstein $\mathrm{m}^{-2} \mathrm{~s}^{-1}$ (or a fluence rate of $\left.3.19 \mathrm{~mW} \mathrm{~cm}^{-2}\right)$, which accounted for $5.6 \%$ of the UV PFR. With the $E_{\mathrm{p}, \mathrm{o}, \mathrm{VUV}}$ available, the $F_{\mathrm{p}, \mathrm{o}, \mathrm{VUV}}$ could be readily calculated with eq 8 .

VUV/UV/Chlorine Process. Figure 4 shows the degradation of $\mathrm{MB}$ in the $\mathrm{UV} /$ chlorine and $\mathrm{VUV} / \mathrm{UV} /$ chlorine processes with $\mathrm{pH}$ uncontrolled ( $\mathrm{pH}$ decreased approximately from 6.4 to 5.5 over the reaction course). The fit lines indicate that all reactions followed pseudo-first-order kinetics. Only a slight degradation was found if the MB solution was exposed to UV or active chlorine alone $\left(k_{\mathrm{U}}^{\prime}=9.0 \mathrm{~m}^{2}\right.$ einstein $^{-1}, k_{\mathrm{Cl}}=3.17$ $\left.\times 10^{-4} \mathrm{~s}^{-1}\right)$. However, a notably higher photon fluence-based reaction rate constant $\left(k_{\mathrm{V} / \mathrm{U}}^{\prime}=268 \mathrm{~m}^{2}\right.$ einstein $\left.^{-1}\right)$ was observed in the $\mathrm{VUV} / \mathrm{UV}$ process because of the additional advanced oxidation by ${ }^{\bullet} \mathrm{OH}$. After spiking active chlorine, the photon fluence-based reaction rate constant increased considerably to $352 \mathrm{~m}^{2}$ einstein $^{-1}\left(k_{\mathrm{U} / \mathrm{Cl}}^{\prime}\right)$ in the $\mathrm{UV} /$ chlorine process and to

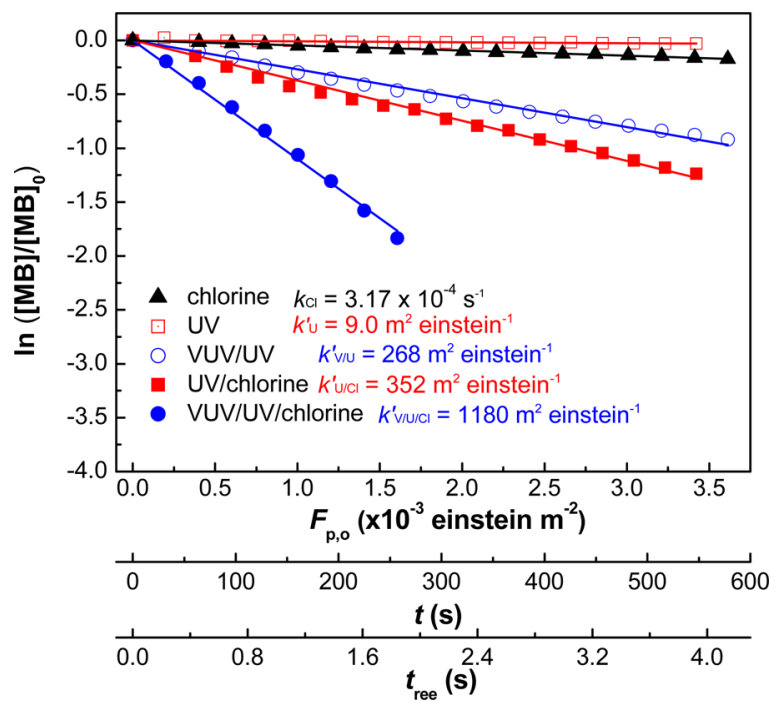

Figure 4. MB degradation by UV/chlorine and VUV/UV/chlorine. Conditions: $[\mathrm{MB}]_{0}=5 \mathrm{mg} \mathrm{L}^{-1}$, $[\text { chlorine }]_{0}=25 \mathrm{mg} \mathrm{L}^{-1}$.

$1,180 \mathrm{~m}^{2}$ einstein $^{-1}\left(k_{\mathrm{V} / \mathrm{U} / \mathrm{Cl}}^{\prime}\right)$ in the $\mathrm{VUV} / \mathrm{UV} /$ chlorine process.

Since little MB was degraded under UV exposure alone and the direct VUV photolysis of $\mathrm{MB}$ was also negligible, the degradation of $\mathrm{MB}$ in the $\mathrm{VUV} / \mathrm{UV} /$ chlorine process could arise from only two parts: (1) oxidation by active chlorine and radicals (e.g., ${ }^{\bullet} \mathrm{OH}$ and $\mathrm{Cl}^{\bullet}$ ) generated from active chlorine exposed to UV (254 nm), and (2) oxidation by ${ }^{\bullet} \mathrm{OH}$ generated from VUV $(185 \mathrm{~nm})$ photolysis of water. The former part was equivalent to the $\mathrm{MB}$ degradation by $\mathrm{UV} /$ chlorine (i.e., in the UV tube), considering that the UV photon fluence was nearly identical in both tubes. The latter part was equivalent to the $\mathrm{MB}$ degradation by VUV/UV (i.e., in the VUV/UV tube) without active chlorine addition. Therefore, in theory, the photon fluence-based rate constant of $\mathrm{MB}$ degradation in the $\mathrm{VUV} / \mathrm{UV} /$ chlorine process $\left(k_{\mathrm{V} / \mathrm{U} / \mathrm{Cl}}^{\prime}\right)$ should be equal to the sum of those in the UV/chlorine and VUV/UV processes (i.e., $\left.k_{\mathrm{U} / \mathrm{Cl}}^{\prime}+k_{\mathrm{V} / \mathrm{U}}^{\prime}\right)$. Nevertheless, the $k_{\mathrm{V} / \mathrm{U} / \mathrm{Cl}}^{\prime}\left(1,180 \mathrm{~m}^{2}\right.$ einstein $\left.{ }^{-1}\right)$ was actually 1.9 times the sum of $k_{\mathrm{V} / \mathrm{U}}^{\prime}\left(268 \mathrm{~m}^{2}\right.$ einstein $\left.{ }^{-1}\right)$ and $k_{\mathrm{U} / \mathrm{Cl}}^{\prime}\left(352 \mathrm{~m}^{2}\right.$ einstein $\left.{ }^{-1}\right)$, manifesting a significant enhancement of the MB degradation by the combined VUV/UV/ chlorine process. Similar tests were also performed by substituting active chlorine with $\mathrm{H}_{2} \mathrm{O}_{2}$, whereas the $\mathrm{MB}$ degradation rate constant in the $\mathrm{VUV} / \mathrm{UV} / \mathrm{H}_{2} \mathrm{O}_{2}$ process $\left(k_{\mathrm{V} / \mathrm{U} / \mathrm{H}}^{\prime}=271 \mathrm{~m}^{2}\right.$ einstein $\left.^{-1}\right)$ was almost equal to the sum of those in the UV/ $\mathrm{H}_{2} \mathrm{O}_{2}\left(k_{\mathrm{U} / \mathrm{H}}^{\prime}=77 \mathrm{~m}^{2}\right.$ einstein $\left.^{-1}\right)$ and VUV/ $\mathrm{UV}\left(k_{\mathrm{V} / \mathrm{U}}^{\prime}=185 \mathrm{~m}^{2}\right.$ einstein $\left.^{-1}\right)$ processes (Figure S1).

Effect of Active Chlorine Dose. The effect of active chlorine dose on $\mathrm{MB}$ degradation by $\mathrm{VUV} / \mathrm{UV} /$ chlorine, UV/ chlorine, $\mathrm{VUV} / \mathrm{UV} / \mathrm{H}_{2} \mathrm{O}_{2}$, and $\mathrm{UV} / \mathrm{H}_{2} \mathrm{O}_{2}$ is shown in Figure 5a. As the active chlorine dose was raised from 0 to $50 \mathrm{mg} \mathrm{L}^{-1}$, both $k_{\mathrm{V} / \mathrm{U} / \mathrm{Cl}}^{\prime}$ and $k_{\mathrm{U} / \mathrm{Cl}}^{\prime}$ increased obviously with the former increasing relatively faster. By contrast, both $k_{\mathrm{V} / \mathrm{U} / \mathrm{H}}^{\prime}$ and $k_{\mathrm{U} / \mathrm{H}}^{\prime}$ increased slowly with increasing $\mathrm{H}_{2} \mathrm{O}_{2}$ dose at a similar pace. To quantitatively assess the enhancement of the combined process (i.e., VUV/UV/chlorine or $\mathrm{VUV} / \mathrm{UV} / \mathrm{H}_{2} \mathrm{O}_{2}$ ) on $\mathrm{MB}$ degradation as compared to the total performance of the two relatively simpler processes [i.e., $\mathrm{UV} /$ chlorine (or $\mathrm{UV} / \mathrm{H}_{2} \mathrm{O}_{2}$ ) plus VUV/UV], an enhancement factor ( $R$, with its subscript denoting a chemical added) was defined as follows: 


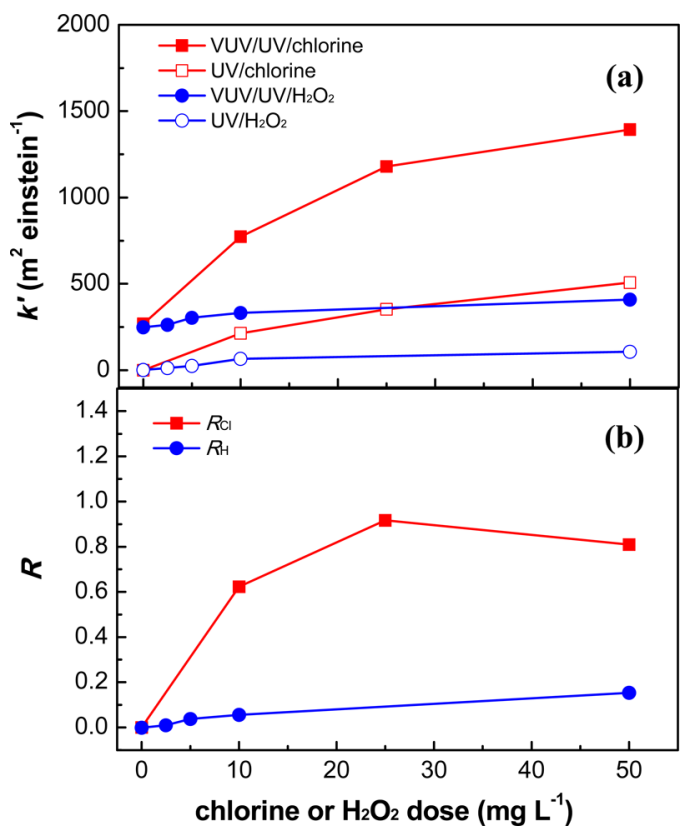

Figure 5. $\mathrm{MB}$ degradation by UV/chlorine, $\mathrm{VUV} / \mathrm{UV} /$ chlorine, $\mathrm{UV} /$ $\mathrm{H}_{2} \mathrm{O}_{2}$, and VUV/UV/ $\mathrm{H}_{2} \mathrm{O}_{2}$ as a function of active chlorine or $\mathrm{H}_{2} \mathrm{O}_{2}$ dose: (a) the photon fluence-based rate constants and (b) the enhancement factor $(R)$. Conditions: $[\mathrm{MB}]_{0}=5 \mathrm{mg} \mathrm{L}^{-1}$.

$$
\begin{aligned}
& R_{\mathrm{Cl}}=\frac{k_{\mathrm{V} / \mathrm{U} / \mathrm{Cl}}^{\prime}}{k_{\mathrm{U} / \mathrm{Cl}}^{\prime}+k_{\mathrm{V} / \mathrm{U}}^{\prime}}-1 \\
& R_{\mathrm{H}}=\frac{k_{\mathrm{V} / \mathrm{U} / \mathrm{H}}^{\prime}}{k_{\mathrm{U} / \mathrm{H}}^{\prime}+k_{\mathrm{V} / \mathrm{U}}^{\prime}}-1
\end{aligned}
$$

Figure $5 \mathrm{~b}$ shows that spiking active chlorine to the VUV/UV process yielded obviously higher $R$ values than spiking $\mathrm{H}_{2} \mathrm{O}_{2}$. Moreover, the $R_{\mathrm{Cl}}$ kept increasing with increasing active chlorine dose until reached a maximum value (i.e., 0.9) at 25 $\mathrm{mg} \mathrm{L}^{-1}$ active chlorine, thereafter it decreased at a higher active chlorine dose $\left(50 \mathrm{mg} \mathrm{L}^{-1}\right)$. By contrast, the $R_{\mathrm{H}}$ kept increasing with increasing $\mathrm{H}_{2} \mathrm{O}_{2}$ dose, but its increase was much slower than that of $R_{\mathrm{Cl}}$. It is well-known that $\mathrm{H}_{2} \mathrm{O}_{2}$ competes for ${ }^{\bullet} \mathrm{OH}{ }^{7}$ and the self-recombination of ${ }^{\bullet} \mathrm{OH}$ resulting from VUV photolysis of water (to form additional $\mathrm{H}_{2} \mathrm{O}_{2}$ ) could further exacerbate this scavenging effect in the $\mathrm{VUV} / \mathrm{UV} / \mathrm{H}_{2} \mathrm{O}_{2}$ process. However, in the $\mathrm{UV} /$ chlorine process, the quantum yield of active chlorine (to produce radicals) increased with increasing active chlorine dose. ${ }^{5}$

Effect of $\mathrm{pH} . \mathrm{MB}$ degradation by UV/chlorine and VUV/ $\mathrm{UV} /$ chlorine was comparatively examined at pHs 5 and 10 . Without irradiation, the solution $\mathrm{pH}$ only showed a slight impact on $\mathrm{MB}$ degradation by active chlorine (Figure S2). However, after exposure to UV or VUV/UV light, the solution $\mathrm{pH}$ could significantly impact $\mathrm{MB}$ degradation (Figure 6). Specifically, under UV exposure alone, $\mathrm{MB}$ was degraded more quickly at $\mathrm{pH} 10\left(k_{\mathrm{U}}^{\prime}=62 \mathrm{~m}^{2}\right.$ einstein $\left.^{-1}\right)$ than at $\mathrm{pH} 5\left(k_{\mathrm{U}}^{\prime}=\right.$ $13 \mathrm{~m}^{2}$ einstein $\left.{ }^{-1}\right)$. By contrast, the VUV/UV process removed $\mathrm{MB}$ more effectively at $\mathrm{pH} 5\left(k_{\mathrm{V} / \mathrm{U}}^{\prime}=365 \mathrm{~m}^{2}\right.$ einstein $\left.{ }^{-1}\right)$ than at $\mathrm{pH} 10\left(k_{\mathrm{V} / \mathrm{U}}^{\prime}=245 \mathrm{~m}^{2}\right.$ einstein $\left.{ }^{-1}\right)$. This could be attributed to two opposite aspects. On the one side, when abundant ${ }^{\circ} \mathrm{OH}$ was generated by VUV photolysis of water, the following reactions could occur: ${ }^{31-33}$

$$
\bullet \mathrm{OH} \rightleftharpoons \mathrm{H}^{+}+\mathrm{O}^{\bullet-}
$$

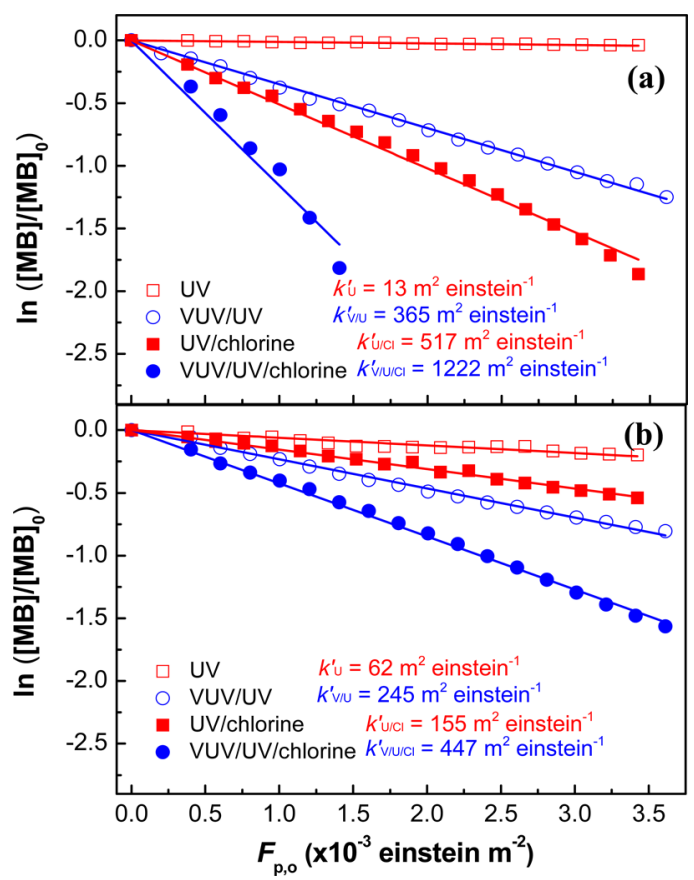

Figure 6. $\mathrm{MB}$ degradation by $\mathrm{UV} /$ chlorine and $\mathrm{VUV} / \mathrm{UV} /$ chlorine as a function of photon fluence at: (a) $\mathrm{pH} 5$; and (b) $\mathrm{pH} 10$. Conditions: $[\mathrm{MB}]_{0}=5 \mathrm{mg} \mathrm{L}^{-1}$, [chlorine $]_{0}=25 \mathrm{mg} \mathrm{L}^{-1}$.

$$
\begin{aligned}
& { }^{\bullet} \mathrm{OH}+{ }^{\bullet} \mathrm{OH} \rightarrow \mathrm{H}_{2} \mathrm{O}_{2} \\
& \mathrm{H}_{2} \mathrm{O}_{2} \rightleftharpoons \mathrm{H}^{+}+\mathrm{HO}_{2}^{-} \\
& \mathrm{HO}_{2}^{-}+{ }^{\circ} \mathrm{OH} \rightarrow \mathrm{H}_{2} \mathrm{O}+\mathrm{O}_{2}^{\bullet-}
\end{aligned}
$$

Reactions 13, 15, and 16 would shift toward the right with increasing $\mathrm{pH}$. Because ${ }^{\bullet} \mathrm{OH}$ was consumed to produce $\mathrm{O}^{\bullet-}$ and $\mathrm{O}_{2}{ }^{\bullet-}$, which have lower oxidation potentials than ${ }^{\circ} \mathrm{OH}$, the $\mathrm{MB}$ degradation would be retarded correspondingly. On the other side, the $\mathrm{pH}$ increase promoted the deprotonation of two side amine moieties in the MB structure (Figure S3), thus facilitating the electrophilic attack of oxidative radicals. The net effect came out to be that MB degradation by VUV/UV slowed down at $\mathrm{pH} 10$ as compared to that at $\mathrm{pH} 5$.

For the UV/chlorine process, its photon fluence-based rate constant at $\mathrm{pH} 5\left(k_{\mathrm{U} / \mathrm{Cl}}^{\prime}=517 \mathrm{~m}^{2}\right.$ einstein $\left.^{-1}\right)$ was about 3.3 times that at $\mathrm{pH} 10\left(k_{\mathrm{U} / \mathrm{Cl}}^{\prime}=155 \mathrm{~m}^{2}\right.$ einstein $\left.^{-1}\right)$, which could arise from the dissociation of $\mathrm{HOCl}$ to $\mathrm{OCl}^{-}(\mathrm{pK}=7.5,25$ ${ }^{\circ} \mathrm{C}$ ). It was reported that under $\mathrm{UV}$ exposure, $\mathrm{HOCl}$ has a higher quantum yield for radical production than does $\mathrm{OCl}^{-4,7}$ thus the $\mathrm{pH}$ decrease enhanced $\mathrm{MB}$ degradation by UV/ chlorine. For the $\mathrm{VUV} / \mathrm{UV} /$ chlorine process, the photon fluence-based rate constant (i.e., $k_{\mathrm{V} / \mathrm{U} / \mathrm{Cl}}^{\prime}$ ) at $\mathrm{pH} 5$ was also significantly higher (2.9 times) than that at $\mathrm{pH} 10$. Overall, the synergistic effect of the $\mathrm{VUV} / \mathrm{UV} /$ chlorine process was stronger at $\mathrm{pH} 5\left(R_{\mathrm{Cl}}=0.4\right)$ than at $\mathrm{pH} 10\left(R_{\mathrm{Cl}}=0.1\right)$.

Effect of NB. Because NB reacts very fast with ${ }^{\bullet} \mathrm{OH}$ $\left(k_{\mathrm{NB}, \bullet \mathrm{OH}}=3.9 \times 10^{9} \mathrm{~s}^{-1}\right)$ but hardly reacts at all with reactive chlorine species (e.g., $\mathrm{Cl}^{\bullet}$ ), ${ }^{4}$ the contributions of ${ }^{\bullet} \mathrm{OH}$ and the reactive chlorine species to $\mathrm{MB}$ degradation could be clarified by adding $\mathrm{NB}$ as an ${ }^{\bullet} \mathrm{OH}$ scavenger. In the presence or absence of $0.5 \mathrm{mM} \mathrm{NB}$, the photon fluence-based rate constants of $\mathrm{MB}$ degradation by $\mathrm{VUV} / \mathrm{UV}, \mathrm{UV} /$ chlorine and $\mathrm{VUV} / \mathrm{UV} /$ chlorine at pHs 5 and 10 are listed comparatively in Table 1 . As expected, under VUV/UV exposure, little $\mathrm{MB}$ was degraded 
Table 1. Pseudo-First-Order Photon Fluence-Based Rate Constants of MB Degradation $\left(k^{\prime}, \mathrm{m}^{2}\right.$ einstein $\left.^{-1}\right)$ by VUV/ $\mathrm{UV}, \mathrm{UV} / \mathrm{Chlorine}$ and VUV/UV/Chlorine

\begin{tabular}{lccccc}
\multirow{2}{*}{\multicolumn{1}{c}{ process }} & \multicolumn{2}{c}{$\mathrm{pH} 5$} & & \multicolumn{2}{c}{$\mathrm{pH} \mathrm{10}$} \\
\cline { 2 - 3 } \cline { 5 - 6 } VUV/UV & without NB & with NB & & without NB & with NB $^{a}$ \\
UV/chlorine & $365^{b}$ & 26 & & 245 & 17 \\
VUV/UV/chlorine & 517 & 149 & & 155 & 51 \\
& 1222 & 432 & & 447 & 130
\end{tabular}

${ }^{a}[\mathrm{NB}]_{0}=0.5 \mathrm{mM} .{ }^{b}$ Each number in this table is a result of the linear regression of $7-20$ experimental data points $\left(R^{2}>99 \%\right)$.

with $\mathrm{NB}$ addition in both acidic and alkaline conditions. Furthermore, in the presence of $\mathrm{NB}$, the photon fluence-based rate constants for $\mathrm{MB}$ degradation by $\mathrm{UV} /$ chlorine and VUV/ $\mathrm{UV} /$ chlorine also decreased. However, a notable portion of $\mathrm{MB}$ was still degraded, because NB could not scavenge the reactive chlorine species generated in the two processes. In the VUV/ $\mathrm{UV} /$ chlorine process, it can be calculated that the relative contributions of ${ }^{\circ} \mathrm{OH}$ and the reactive chlorine species to $\mathrm{MB}$ degradation were $63 \%$ and $35 \%$ at $\mathrm{pH} \mathrm{5}$, and $67 \%$ and $29 \%$ at $\mathrm{pH} 10$, respectively. The direct photolysis only contributed to $2 \%$ and $4 \%$ of $\mathrm{MB}$ degradation at $\mathrm{pHs} 5$ and 10 , respectively.

Synergistic Mechanism of VUV/UV/chlorine. In most AOPs (e.g., $\mathrm{UV} / \mathrm{H}_{2} \mathrm{O}_{2}$ and $\mathrm{UV} / \mathrm{O}_{3}$ ), reactive species are distributed quite uniformly in aqueous solution. Nevertheless, for the VUV/UV process, because of the low penetration depth of the $185 \mathrm{~nm}$ VUV in water, a majority of reactive species (i.e., ${ }^{\bullet} \mathrm{OH}$ and $\mathrm{H}^{\bullet}$ ) are formed in the region near the quartz sleeve (i.e., the near-field region), whereas much less reactive species are formed in the region with a larger distance from the quartz sleeve (i.e., the far-field region). Hence, in the near-field region, the ${ }^{\bullet} \mathrm{OH}$ and $\mathrm{H}^{\bullet}$ with a high local concentration tend to induce the formation of $\mathrm{H}_{2} \mathrm{O}_{2}$ (eq 14) and $\mathrm{H}_{2}$ (eq 17) ${ }^{34}$ arising from their self-recombination reactions.

$$
\mathrm{H}^{\bullet}+\mathrm{H}^{\bullet} \rightarrow \mathrm{H}_{2}, \quad k_{\mathrm{H}^{\bullet}}=1 \times 10^{10} \mathrm{M}^{-1} \mathrm{~s}^{-1}
$$

To test the formation of $\mathrm{H}_{2} \mathrm{O}_{2}$, Milli-Q water was exposed to VUV/UV irradiation in the MVPS, and $0.59 \mathrm{mg} \mathrm{L}^{-1} \mathrm{H}_{2} \mathrm{O}_{2}$ was detected at a photon fluence of $2.28 \times 10^{-2}$ einstein $\mathrm{m}^{-2}$ (Figure 7). Imoberdorf and Mohseni ${ }^{12}$ also reported that up to $0.32 \mathrm{mM} \mathrm{H}_{2} \mathrm{O}_{2}$ was generated in an annular VUV/UV reactor after a long exposure time of $40 \mathrm{~min}$. By contrast, with addition

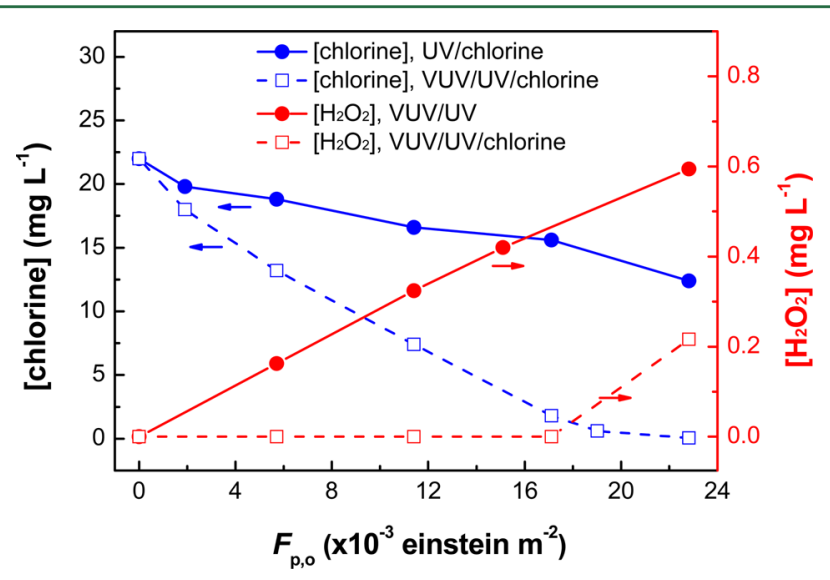

Figure 7. Chlorine consumption and $\mathrm{H}_{2} \mathrm{O}_{2}$ formation in the VUV/ $\mathrm{UV}, \mathrm{UV} /$ chlorine, and VUV/UV/chlorine processes. Conditions: $[\text { chlorine }]_{0}=25 \mathrm{mg} \mathrm{L}^{-1}$. of $25 \mathrm{mg} \mathrm{L} \mathrm{L}^{-1}$ active chlorine to the $\mathrm{VUV} / \mathrm{UV}$ process (i.e., $\mathrm{VUV} / \mathrm{UV} /$ chlorine), the formation of $\mathrm{H}_{2} \mathrm{O}_{2}$ was greatly inhibited until the depletion of active chlorine (Figure 7). Thereafter, $\mathrm{H}_{2} \mathrm{O}_{2}$ started to appear and reached $0.21 \mathrm{mg} \mathrm{L}^{-1}$ at a photon fluence of $2.28 \times 10^{-2}$ einstein $\mathrm{m}^{-2}$. Accordingly, active chlorine was consumed much faster in the VUV/UV/ chlorine process than in the $\mathrm{UV} /$ chlorine process. This implies that in the $\mathrm{VUV} / \mathrm{UV} /$ chlorine process, the abundant ${ }^{\circ} \mathrm{OH}$ in the near-field region could further react with $\mathrm{HOCl} / \mathrm{OCl}^{-}$to produce secondary radicals such as ${ }^{\circ} \mathrm{OCl}$ (eqs 18 and 19) ${ }^{4}$ instead of forming $\mathrm{H}_{2} \mathrm{O}_{2}$ (eq 14). These secondary radicals could live longer and migrate for a larger distance to attack $\mathrm{MB}$ molecules available in the far-field region of the bulk solution. Hence, through addition of active chlorine, the ${ }^{\bullet} \mathrm{OH}$ generated from VUV photolysis of water was mostly used for pollutant removal rather than ending up in the ineffective $\mathrm{H}_{2} \mathrm{O}_{2}$. This may explain the synergistic effect observed in the VUV/UV/ chlorine process.

$$
\begin{aligned}
& { }^{\circ} \mathrm{OH}+\mathrm{HOCl} \rightarrow{ }^{\circ} \mathrm{OCl}+\mathrm{H}_{2} \mathrm{O} \\
& { }^{\bullet} \mathrm{OH}+\mathrm{OCl}^{-} \rightarrow{ }^{\bullet} \mathrm{OCl}+\mathrm{OH}^{-}
\end{aligned}
$$

The effect of active chlorine dose is also manifested in Figure 5. When the active chlorine dose increased from 0 to $25 \mathrm{mg}$ $\mathrm{L}^{-1}$, the primary radicals $\left({ }^{\bullet} \mathrm{OH}\right)$ could react with $\mathrm{HOCl} / \mathrm{OCl}^{-}$ to produce the secondary radicals (e.g., ${ }^{\bullet} \mathrm{OCl}$ ) as aforementioned, thus causing a rapid increase in the $R_{\mathrm{Cl}}$ due to their larger migration distance (Figure $5 \mathrm{~b}$ ). However, when the active chlorine dose further increased to $50 \mathrm{mg} \mathrm{L}^{-1}$, the $R_{\mathrm{Cl}}$ decreased to some extent. This probably arises from three aspects: (1) at a high active chlorine concentration, the primary - $\mathrm{OH}$ in the near-field region was completely consumed by $\mathrm{MB}$ and $\mathrm{HOCl} / \mathrm{OCl}^{-}$, so the secondary radicals already reached a maximum concentration; (2) the secondary radicals had a relatively weaker oxidation potential than ${ }^{\bullet} \mathrm{OH}$ (e.g., ${ }^{\bullet} \mathrm{OCl}$ vs ' $\mathrm{OH}$ ); and (3) with the availability of abundant $\mathrm{HOCl} / \mathrm{OCl}^{-}$, some tertiary reactive species (e.g., $\mathrm{Cl}_{2}{ }^{\bullet-}$ ) might be formed, which could only react slowly with $\mathrm{MB}$.

In addition, the synergistic effect of the $\mathrm{VUV} / \mathrm{UV} /$ chlorine process could also arise from the VUV photolysis of $\mathrm{HOCl} /$ $\mathrm{OCl}^{-}$(eq 20), although VUV photons react much faster toward $\mathrm{H}_{2} \mathrm{O}$. Table 1 shows that in the presence of $\mathrm{NB}$, the $k_{\mathrm{V} / \mathrm{U} / \mathrm{Cl}}^{\prime}$ was 2.9 and 2.5 times the $k_{\mathrm{U} / \mathrm{Cl}}^{\prime}$ at $\mathrm{pH} 5$ and 10 , respectively. This implies that after completely scavenging ${ }^{\bullet} \mathrm{OH}$, a higher $\mathrm{Cl}^{\bullet}$ concentration could be expected in the $\mathrm{VUV} / \mathrm{UV} /$ chlorine process than in the UV/chlorine process, which led to a much faster $\mathrm{MB}$ degradation.

$$
\mathrm{HOCl} \stackrel{h v_{185}}{\longrightarrow} \mathrm{OH}+\mathrm{Cl}^{\bullet}
$$

Discussion on MVPS. The MVPS is a new bench-scale apparatus for fundamental photoreaction studies. Although it cannot solely deliver VUV (185 nm) irradiation, it can output $\mathrm{VUV} / \mathrm{UV}$ and UV beams with a nearly identical UV photon fluence in the two test tubes through special design of the optical structure, thus enabling studies on the net effect of VUV irradiation. Hence, the MVPS provides a powerful tool to compare quantitatively the treatment efficiencies of UV- and VUV/UV-based AOPs in the presence or absence of an assistant chemical (e.g., active chlorine), where UV often plays an important role in pollutant removal by forming reactive species and by direct photolysis as well. In addition, the two test tubes (i.e., VUV/UV and UV tubes) are installed close to the lamp (about $5 \mathrm{~mm}$ to the lamp surface), which gives rise to a 
high UV PFR $\left[8.88 \times 10^{-4}\right.$ einstein $\mathrm{m}^{-2} \mathrm{~s}^{-1}$ (or a fluence rate of $41.8 \mathrm{~mW} \mathrm{~cm}^{-2}$ ) at $254 \mathrm{~nm}$ ] and a short reaction time correspondingly. Further assisted with an online spectrophotometer, the MVPS can quickly determine the reaction kinetics under VUV/UV exposure, with a significant reduction in both experimental workload and operational error.

Compared with a cylindrical batch VUV/UV reactor, the MVPS has a much shorter optical path-length $(2 \mathrm{~mm}$ inner diameter, and even a thinner tube can be selected). Because the background UV absorbance of water sample induces a PFR attenuation along the radial distance of the lamp according to the Lambert-Beer Law, a smaller variance of UV PFR (i.e., $\left.E_{\mathrm{p}, \mathrm{o}, \mathrm{UV}}\right)$ within the cross-section of the test tube in the MVPS can be reasonably expected than that in a batch reactor. Moreover, by recirculating water of a constant temperature through the outer chamber of the photoreactor (to maintain a stable mercury vapor pressure in the lamp) and online monitoring the lamp output with an MFSD as well, a stable UV output is ensured during each experiment. Therefore, the UV photon fluence in the MVPS can be determined more accurately than that in a batch reactor.

Note that the MVPS adopts an operation mode of intermittent light exposure, that is, $t_{\text {ree }}$ is only a part of the total reaction time $(t)$. For some complex reactions whose photoreaction (dependent on light) and dark-reaction (independent of light) rates are comparable, intermittent light exposure may induce a certain error in kinetic measurements. Under this circumstance, the dark-reaction rate needs to be measured separately by a control experiment, and then the overall kinetic parameters obtained from the MVPS should be corrected based on relevant kinetic model calculations. In the present study, because the rate constant of $\mathrm{MB}$ degradation by active chlorine in the dark was much smaller than those of photoreactions (Figure 4), intermittent light exposure would not induce a problem.

Discussion on VUV/UV/Chlorine. The low VUV output has long been regarded as the principal limitation for its practical applications to water treatment. ${ }^{9}$ Hence, a majority of research efforts have been made to enhance the VUV output, such as increasing the VUV transmittance of the quartz used for lamp wall and sleeve, raising the total power of the lamp, and inventing new light sources for VUV irradiation. However, unfortunately, to date, no significant progress has been made. This study, for the first time, demonstrates that the treatment efficiency of the VUV/UV process can be simply but greatly improved by addition of active chlorine. Because the new $\mathrm{VUV} / \mathrm{UV} /$ chlorine process is easy to apply, highly efficient, and energy saving, it has a promising prospect for small-scale water and wastewater treatment.

\section{ASSOCIATED CONTENT}

\section{S Supporting Information}

The Supporting Information is available free of charge on the ACS Publications website at DOI: 10.1021/acs.est.6b00133.

(Figure S1) $\mathrm{MB}$ degradation by $\mathrm{UV} / \mathrm{H}_{2} \mathrm{O}_{2}$ and $\mathrm{VUV} /$ $\mathrm{UV} / \mathrm{H}_{2} \mathrm{O}_{2}$; (Figure S2) $\mathrm{MB}$ degradation by active chlorine in the dark; and (Figure S3) molecular structure of $\mathrm{MB}$; and additional references (PDF)

\section{AUTHOR INFORMATION}

\section{Corresponding Author}

*Phone: +86 10 62849632; fax: +86 10 62923541; e-mail: qiangz@rcees.ac.cn (Z. Qiang).

\section{Notes}

The authors declare no competing financial interest.

\section{ACKNOWLEDGMENTS}

This work was financially supported by the National Natural Science Foundation of China (51408592, 51525806, 51221892) and the National Geographic Air and Water Conservation Fund (GEFC23-15).

\section{REFERENCES}

(1) Keen, O. S.; McKay, G.; Mezyk, S. P.; Linden, K. G.; RosarioOrtiz, F. L. Identifying the factors that influence the reactivity of effluent organic matter with hydroxyl radicals. Water Res. 2014, 50, 408-419.

(2) Watts, M. J.; Linden, K. G. Chlorine photolysis and subsequent $\mathrm{OH}$ radical production during UV treatment of chlorinated water. Water Res. 2007, 41 (13), 2871-2878.

(3) Weng, S. C.; Blatchley, E. R. Ultraviolet-induced effects on chloramine and cyanogen chloride formation from chlorination of amino acids. Environ. Sci. Technol. 2013, 47 (9), 4269-4276.

(4) Fang, J. Y.; Fu, Y.; Shang, C. The roles of reactive species in micropollutant degradation in the UV/free chlorine system. Environ. Sci. Technol. 2014, 48 (3), 1859-1868.

(5) Feng, Y. G.; Smith, D. W.; Bolton, J. R. Photolysis of aqueous free chlorine species $\left(\mathrm{HOCl}\right.$ and $\left.\mathrm{OCl}^{-}\right)$with $254 \mathrm{~nm}$ ultraviolet light. $J$. Environ. Eng. Sci. 2007, 6 (3), 277-284.

(6) Jin, J.; El-Din, M. G.; Bolton, J. R. Assessment of the UV/chlorine process as an advanced oxidation process. Water Res. 2011, 45 (4), $1890-1896$

(7) Wang, D.; Bolton, J. R.; Andrews, S. A.; Hofmann, R. Medium pressure UV combined with chlorine advanced oxidation for trichloroethylene destruction in a model water. Water Res. 2012, 46 (15), 4677-4686.

(8) Weeks, J. L.; Meaburn, G. M. A.; Gordon, S. Absorption coefficients of liquid water and aqueous solutions in far ultraviolet. Radiat. Res. 1963, 19 (3), 559-567.

(9) Zoschke, K.; Bornick, H.; Worch, E. Vacuum-UV radiation at 185 $\mathrm{nm}$ in water treatment - A review. Water Res. 2014, 52, 131-145.

(10) Oppenländer, T. Photochemical Purification of Water and Air; Wiley-VCH: Weinheim, Germany, 2003; pp 368.

(11) Buchanan, W.; Roddick, F.; Porter, N.; Drikas, M. Fractionation of UV and VUV pretreated natural organic matter from drinking water. Environ. Sci. Technol. 2005, 39 (12), 4647-4654.

(12) Imoberdorf, G.; Mohseni, M. Degradation of natural organic matter in surface water using vacuum-UV irradiation. J. Hazard. Mater. 2011, 186 (1), 240-246.

(13) Li, W. Z.; Lu, S. G.; Chen, N.; Gu, X. G.; Qiu, Z. F.; Fan, J.; Lin, K. F. Photo-degradation of clofibric acid by ultraviolet light irradiation at $185 \mathrm{~nm}$. Water Sci. Technol. 2009, 60 (11), 2983-2989.

(14) Chen, J.; Zhang, P. Y.; Liu, J. Photodegradation of perfluorooctanoic acid by $185 \mathrm{~nm}$ vacuum ultraviolet light. J. Environ. Sci. 2007, 19 (4), 387-390.

(15) Kim, I.; Tanaka, H. Photodegradation characteristics of PPCPs in water with UV treatment. Environ. Int. 2009, 35 (5), 793-802.

(16) Duca, C.; Imoberdorf, G.; Mohseni, M. Novel collimated beam setup to study the kinetics of VUV-induced reactions. Photochem. Photobiol. 2014, 90 (1), 238-240.

(17) Wang, D.; Oppenländer, T.; El-Din, M. G.; Bolton, J. R. Comparison of the disinfection effects of vacuum-UV (VUV) and UV light on bacillus subtilis spores in aqueous suspensions at 172, 222 and $254 \mathrm{~nm}$. Photochem. Photobiol. 2010, 86 (1), 176-181. 
(18) Collivignarelli, C.; Sorlini, S. AOPs with ozone and UV radiation in drinking water: Contaminants removal and effects on disinfection byproducts formation. Water Sci. Technol. 2004, 49 (4), 51-56.

(19) Echigo, S.; Yamada, H.; Matsui, S.; Kawanishi, S.; Shishida, K. Comparison between $\mathrm{O}_{3} / \mathrm{VUV}, \mathrm{O}_{3} / \mathrm{H}_{2} \mathrm{O}_{2}$, VUV and $\mathrm{O}_{3}$ processes for the decomposition of organophosphoric acid triesters. Water Sci. Technol. 1996, 34 (9), 81-88.

(20) Han, W. Y.; Zhang, P. Y.; Zhu, W. P.; Yin, J. J.; Li, L. S. Photocatalysis of $p$-chlorobenzoic acid in aqueous solution under irradiation of 254 and $185 \mathrm{~nm}$ UV light. Water Res. 2004, 38 (19), 4197-4203.

(21) Qiang, Z. M.; Li, M. K.; Bolton, J. R. Development of a triparameter online monitoring system for $\mathrm{UV}$ disinfection reactors. Chem. Eng. J. 2013, 222, 101-107.

(22) Li, M. K.; Qiang, Z. M.; Wang, C.; Bolton, J. R.; Lian, J. F. Development of monitored tunable biodosimetry for fluence validation in an ultraviolet disinfection reactor. Sep. Purif. Technol. 2013, 117, 12-17.

(23) Li, M. K.; Qiang, Z. M.; Li, T. G.; Bolton, J. R.; Liu, C. L. In situ measurement of UV fluence rate distribution by use of a micro fluorescent silica detector. Environ. Sci. Technol. 2011, 45 (7), 30343039.

(24) Li, M. K.; Qiang, Z. M.; Bolton, J. R.; Qu, J. H.; Li, W. T. A mini-fluidic UV photoreaction system for bench-scale photochemical studies. Environ. Sci. Technol. Lett. 2015, 2 (10), 297-301.

(25) Giannakis, S.; Vives, F. A. G.; Grandjean, D.; Magnet, A.; De Alencastro, L. F.; Pulgarin, C. Effect of Advanced Oxidation Processes on the micropollutants and the effluent organic matter contained in municipal wastewater previously treated by three different secondary methods. Water Res. 2015, 84, 295-306.

(26) Eaton, A. D.; Franson, M. A. H. American Public Health Association, Standard Methods for the Examination of Water and Wastewater, $19^{\text {th }}$ ed.; American Public Health Association: Washington, DC, 1995.

(27) Scholes, M. L.; Schuchmann, M. N.; von Sonntag, C. Enhancement of radiation-induced base release from nucleosides in alkaline-solution - Essential role of the $\mathrm{O}^{\bullet-}$ radical. Int. J. Radiat. Biol. 1992, 61 (4), 443-449.

(28) Oppenländer, T.; Schwarzwalder, R. Vacuum-UV oxidation $\left(\mathrm{H}_{2} \mathrm{O}-\mathrm{VUV}\right)$ with a xenon excimer flow-trough lamp at $172 \mathrm{~nm}$ : Use of methanol as actinometer for VUV intensity measurement and as reference compound for $\mathrm{OH}$-radical competition kinetics in aqueous systems. J. Adv. Oxi. Technol. 2002, 5 (2), 155-163.

(29) Jin, S.; Mofidi, A. A.; Linden, K. G. Polychromatic UV fluence measurement using chemical actinometry, biodosimetry, and mathematical techniques. J. Environ. Eng. 2006, 132 (8), 831-841.

(30) Duca, C. Effect of water matrix on vacuum UV process for the removal of organic micropollutants in surfacewaer. Ph.D. thesis; University of British Columbia: Vacouver, Canada, 2015.

(31) Ratpukdi, T.; Siripattanakul, S.; Khan, E. Mineralization and biodegradability enhancement of natural organic matter by ozoneVUV in comparison with ozone, VUV, ozone-UV, and UV: Effects of $\mathrm{pH}$ and ozone dose. Water Res. 2010, 44 (11), 3531-3543.

(32) Kruithof, J. C.; Kamp, P. C.; Martijn, B. J. UV/ $\mathrm{H}_{2} \mathrm{O}_{2}$ treatment: A practical solution for organic contaminant control and primary disinfection. Ozone: Sci. Eng. 2007, 29 (4), 273-280.

(33) Ma, C. M.; Hong, G. B.; Chen, H. W.; Hang, N. T.; Shen, Y. S. Photooxidation contribution study on the decomposition of azo dyes in aqueous solutions by VUV-based AOPs. Int. J. Photoenergy 2011, 2011, 1-8.

(34) Imoberdorf, G.; Mohseni, M. Modeling and experimental evaluation of vacuum-UV photoreactors for water treatment. Chem.

Eng. Sci. 2011, 66 (6), 1159-1167. 